\title{
Drug eluting balloons for treatment of femoropopliteal disease
}

\author{
Umair JM Khan', Aayla K Jamil'², Irfan Ullah ${ }^{3}$ and Muhammad A Khan ${ }^{3,4}$ \\ ${ }^{1}$ Saint George's University Medical School, Grenada, USA \\ ${ }^{2}$ Baylor University Medical Center, Dallas, USA \\ ${ }^{3}$ North Dallas Research Associates, McKinney, Texas, USA \\ ${ }^{4}$ Medical Center of Plano, Texas, USA
}

\begin{abstract}
The VIVA Physicians conference for vascular medicine and intervention, held on November 4, 2014 in Las Vegas, Nevada, highlighted the results of a few late breaking clinical trials. Among the studies presented, quite a few were on drug coated balloon/drug eluting balloon devices for peripheral artery disease of the lower extremity femoropopliteal artery. Peripheral artery disease is a life-threatening condition that reduces blood flow to the lower limb. The American Heart Association estimates that peripheral artery disease affects eight million Americans. The aim of both invasive and noninvasive treatments is to improve the blood flow to the limb and maintain patency of the affected vessel for longer periods of time. Almost 700,000 patients in USA and Western Europe each year undergo an interventional procedure for peripheral artery disease, particularly superficial femoral artery [1]. Percutaneous transluminal angioplasty is the first line of treatment for peripheral artery disease according to the American College of Cardiology. Percutaneous transluminal angioplasty procedure may include balloon dilatation, with or without stent placement. Drug eluting stents and balloons, along with other different types of balloons are being studied to improve peripheral artery disease treatment outcomes, even in difficult lesions. This is a review of scientific evidence supporting percutaneous transluminal angioplasty for PAD with emphasis on drug eluting balloons.
\end{abstract}

\section{Introduction}

Ischemic injury can be caused in any part of the body where vascular supply is compromised. Limbs may be affected by acute limb ischemia due to thrombosis, embolism, dissection or trauma. Critical limb ischemia occurs when the condition becomes advanced and the survival of the limb is threatened due to lack of blood flow. Critical Limb Ischemia (CLI) is associated with rest pain, non-healing ulcers and gangrene. Ischemia is caused by Peripheral Artery Disease (PAD) in limbs due to plaque forming atherosclerosis. Atherosclerosis can lead to thrombosis and partial or complete occlusion of the arterial vessel [2]. According to the CDC, 8 million people in the US are suffering from PAD with almost 20 percent above the age of 60 years [3]. CLI is an extreme form of PAD and requires vascular intervention to prevent severe sequelae. PAD is more common in the legs than arms. Risk factors for PAD include diabetes, high cholesterol, hypertension, smoking, atherosclerosis and age older than 60 years [3]. PAD is classified according to Fontaine and Rutherford classification [4] (Appendix A).

\section{Pad and Critical Limb Ischemia}

Critical Limb Ischemia (CLI) is defined when the symptoms are chronic and present for more than two weeks. It is usually diagnosed by the Ankle Brachial Index (ABI) which a measure of the difference in the ankle and brachial blood pressure. Normal ABI ranges from 1.00 to 1.40 with an abnormal ABI measure of 0.90 and less. ABI of more than 1.40 indicates non-compressible vessel [4].

Claudication is a typical symptom of PAD causing CLI. Initially intermittent claudication may be present with aches, pains, cramping, or uncomfortable feeling in the legs on walking and is relieved with rest. It may be felt in any part of the leg like the thigh, hip, buttock, calf or foot. As the disease progresses the onset of claudication symptoms occurs sooner on walking till a time comes when pain is present even at rest. Rest pain indicates development of irreversible ischemia in the legs. According to the Merck Manual, 20 percent of the patients may be asymptomatic due to their sedentary lifestyle [5]. In moderate to severe PAD there may be diminished or absent peripheral pulses. The skin may be pale or dusky red with loss of hair and there may be muscle atrophy. As the condition worsens, non-healing ulcers and sores may develop especially upon trauma. Gangrene may also occur. Patients with peripheral neuropathy due to diabetes or alcoholism may not even feel any pain. Concomitant infection may lead to cellulitis. Signs and symptoms usually develop distal to the level of occlusion. PAD in the legs is diagnosed by ABI, ultrasound and angiography [5]. Risk factor modification, ACE inhibitors, antiplatelet medication, medication for claudication relief and smoking cessation are among the noninterventional treatment regimens for CLI. When CLI develops with ulcers, claudication at rest, or gangrene then surgical intervention (minimally invasive or invasive) is needed to relieve the arterial blood flow occlusion and to salvage the limb and toes to avoid amputation and premature death.

*Correspondence to: Aayla Jamil, Baylor University Medical Center, 3410 Worth Street, Suite 560, Dallas, USA, Tel: 1-214-960-032; E-mail: Aayla.Jamil@ BSWHealth.org

Received: September 26, 2018; Accepted: October 12, 2018; Published: October 16,2018 
PAD in the lower limb due to atherosclerosis may cause aortoiliac disease (inflow disease), common femoral artery lesions (CFA), Superficial Femoral Artery (SFA) and popliteal artery disease, or tibial and peroneal artery disease [6]. It can be treated using minimally invasive endovascular procedures by interventional radiologists. These treatments include Percutaneous Transluminal Angioplasty (PTA) with balloon inflation, PTA with stent placement, laser angioplasty, atherectomy and Catheter Directed Thrombolysis (CDT). Severe and non-responsive cases may need to be surgically treated. The vascular surgeons either remove the blockage or perform bypass surgery for the affected artery by grafting a vein from the patient or by using a synthetic graft. An algorithm by Kenneth Oriel, MD, at The Cleveland Clinic in Ohio, demonstrates the management of patients with severe lower extremity PAD [7] (Figure 1).

\section{Types of endovascular interventions}

Stents are metallic cylindrical tubes placed inside the artery with the help of a catheter during a PTA procedure. It is used for long lesions and tortuous vessels. A stent holds the artery open after it has been cleared of the obstruction and then expanded by a balloon catheter. Stent is placed when there is failure of PTA procedure. PTA may be done with balloon expansion of the artery alone, without requiring the placement of a stent. PTA is useful to treat short concentric segments of stenosis. Upto $10 \mathrm{~cm}$ of lesions can also be treated by balloon dilatation [5]. PTA cannot be used to treat small arteries or long occlusions. Following PTA antiplatelet medication is taken for life to maintain patency of the artery. In laser angioplasty, pulsed bursts of ultraviolet energy are transmitted via a catheter to dissolve the occluding clot [8]. Atherectomy or thromboendarterectomy is a procedure during which plaque is shaved from the inside of the artery using a small catheter. It is done for short lesions in the aortoiliac, common femoral and deep femoral arteries [5]. For catheter directed thrombolysis (CDT), thrombolytic drugs like urokinase, alteplase, and reteplase are injected into the thrombotic clot via a catheter to dissolve the clot [7]. CDT is done to treat cases of Acute Limb Ischemia (ALI) which present within 2 weeks of the obstruction. ALI may develop due to trauma, embolism, thrombosis, graft thrombosis, and peripheral aneurysm with an embolus or thrombosis [4]. ALI due to graft failure with thrombosis

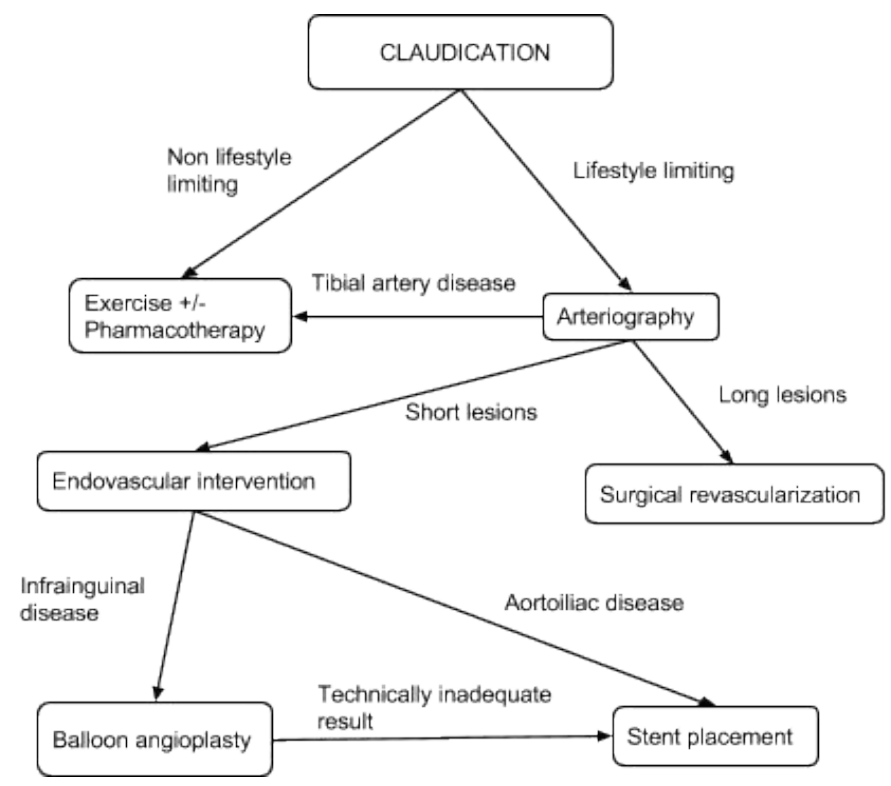

Figure 1. CLI management algorithm [7] may also be treated with PTA, stent placement and surgical revision. Mechanical thrombectomy is another method where the clot is sucked out with a catheter [9].

The TransAtlantic Inter Society Consensus (TASC I) document established recommendations for diagnosis and management of PAD in the lower extremity, which later had an updated consensus document in 2007 (TASC II). TASC classifies femoropopliteal disease according to four types of lesions [4] (Appendix B). For TASC A lesions treatment is endovascular therapy which encompasses PTA. For TASC B endovascular therapy is preferred method of treatment but depends on comorbidities. In case of TASC C and TASC D, surgical intervention like bypass and endarterectomy are the recommended treatments [10]. Generally asymptomatic stenosis is not treated with PTA. PTA should be considered in cases with critical limb ischemia, intermittent claudication limiting ability to work, lifestyle limitations, or as an adjunct for cardiac rehabilitation.

\section{PTA Using Balloon Technologies}

Percutaneous transluminal angioplasty was developed in the 1960's by the innovative works of Thomas Fogarty and Charles Dotter. In 1961 the balloon embolectomy catheter was introduced by Thomas Fogarty to remove an embolus. In 1964 Charles Dotter used this catheter technique to treat atherosclerotic stenosis. He passed an 8 French (F) tetrafluoroethylene (Teflon) catheter into a stenotic vessel and then passed a $12 \mathrm{~F}$ Teflon catheter over it to dilate the vessel. In 1965 Dotter used the first balloon catheter made by Fogarty to treat a case of iliac stenosis. This catheter had two balloons one over the other for extra thickness. Thus, Fogarty was the inventor of the first minimally invasive surgical device while Dotter is known as the father of interventional radiology. These two created a whole new revolutionary chapter in the field of vascular interventional therapy. In 1974 Andreas Grüntzig used polyvinyl chloride in place of latex as the balloon material which made the catheter more flexible than the stiff Teflon catheters and allowed more force to act on the plaque [11]. Ingemar Henry Lundquist developed the over the wire balloon used for angioplasty procedures [12].

Various types of balloons are being made now a days. Most balloons used these days are made of polyethylene terephthalate and other strong plastic polymers. Balloons made of stiff materials like woven nylon are used for tight calcified stenotic sites. Cryoballoons stop the inflammatory response of smooth muscle cells by generating cold temperature and thus reducing the rate of restenosis. Cutting balloons form controlled fault lines in the plaque by 3-4 small cutting blades that create longitudinal cuts into the fibrotic material and allows the vessel to be dilated with lesser force, thereby decreasing the inflammatory response and risk of restenosis [11]. Drug delivering balloons, derived from the principles of drug coated stents, are a new development in the field of balloon angioplasty. Basic principle of drug eluting balloons is local release of drug to resist smooth muscle proliferation after dilatation of the artery. Porous or double balloons may be used. Porous balloons deliver drug locally to the lesion via pores, while with double balloons two balloons block the proximal and distal end of the lesion to bathe the area in between the balloons with the drug.

\section{Drug Eluting Stents (DES)}

Drug eluting stents (DES) have been under research since the 1990's. For coronary artery lesions the US FDA approved the Sirolimus Eluting Stent (SES) Cypher by Cordis, Johnson and Johnson in 2003. Sirolimus (rapamycin) is an antibiotic with powerful immunosuppressive 
property. Paclitaxel (Antiproliferative Agent) Eluting Stent (PES) Taxus by Boston Scientific, Natick, was introduced in 2004 [13]. Zotarolimus (Sirolimus analogue) eluting stent (ZES) Endeavor by Medtronic, and Everolimus eluting stent (EES) Xience V by Guidant, Abbot Vascular are also approved for use in the US [14]. Despite all the above coronary drug eluting stents, Zilver PTX by Cook Medical is the only paclitaxel eluting stent approved for use in femoropopliteal disease [15]. The need for prolonged dual antiplatelet therapy, late stent thrombosis, stent fracture, and stent restenosis brought about the need for improved treatment modalities. Drug eluting balloon has been considered as an alternative to Drug Eluting Stent (DES). DEB can be useful in cases where DES cannot be used, like long calcified plaques, tortuous vessels, bifurcations, and small vessels. The drug release can be done without the use of a polymer, which is needed by some DES which can cause chronic inflammation and late thrombosis. DES has a slower rate of drug release than DEB.

\section{Paclitaxel for Drug Eluting Balloons (DEB)}

Paclitaxel has been identified as an ideal drug for DEB due to its lipophilic property causing rapid uptake and absorption by the arterial luminal surface, and prolonged retention of up to one week [16]. Some of the inactive agents for paclitaxel transfer are the contrast agent iopromide, urea, polysorbate and sorbitol. Paclitaxel has less impact on long term inflammatory response and the balloon transfers drug homogeneously to the vessel wall. Without the presence of the stent polymer, there is a reduction in chronic inflammation and thrombosis. Need for aggressive antiplatelet therapy is decreased with local drug availability. There are different ways to deliver drugs via balloon. These include using nanoparticles loaded with the drug, spraying, dipping and imprinting drug onto the rough surface of the balloon. Drug release kinetics with various doses, the percentage of drug release at varying balloon inflation timings and frequencies are important for the safety and efficacy of the procedure. Ensuring drug delivery to the lesion site and not losing it before the balloon reaches the lesion site is also crucial [14].

\section{Trials for Drug Eluting/Coated Balloons (DEB / DCB)}

In 1999 Ulrich Speck from Charite Hospital, Berlin, Germany, and Bruno Sheller from Saarland University Hospital, Homburg, Germany, added an antiproliferative drug to a contrast agent that served as a carrier for the drug to the vessel. In 2001 experimentation with drug coated balloons for drug delivery to lesion specific sites rather than the whole vessel began, with animal trials starting in 2002 [17]. The Paccocath technology was developed by Speck and Sheller and is owned by Bayer Schering Pharma AG, developed and marketed by Medrad International as Cotavance $^{\mathrm{ntat}}$ [18]. In December 2003 the first patient was enrolled in the coronary Paccocath ISR (In Stent Restenosis) I / II trial. In this technology paclitaxel is embedded in hydrophilic iopromide contrast agent Ultravist 370 to increase the solubility and ease of transfer to the vessel wall [16]. Initial dose of 10 to 15 percent of the drug is delivered to the vessel wall on 60 second inflation.

The THUNDER trial (Local Taxane with Short Exposure for Reduction of Restenosis in Distal Arteries) started in 2004 by Gunar Tepe at the University Hospital of Tuebingen, Germany, gave the first data on DEB angioplasty of the leg using Paclitaxel (Taxane) [17]. One hundred and fifty-four (154) patients with stenosis or occlusion of the superficial femoral or popliteal artery were enrolled and evaluated for restenosis following treatment with either DCB or conventional PTA at 6,12 , and 24 month follow up. The results of the THUNDER trial were published in 2008 in The New England Journal of Medicine. It was a double-blind study using either paclitaxel coated balloons, paclitaxel delivered through contrast medium, or controls with uncoated catheters. The paclitaxel balloon treated restenosis at six months was 17 percent while that in the control group was 44 percent $(p=0.01)$ [19]. At 12 months TLR in the DCB group was 10 percent compared to 48 percent in the control group, and revascularization remained significantly low even at 24 months (15 percent versus 52 percent) with the difference being statistically significant at a $P$ value of less than $0.001[20]$.

The FemPac (Femoral Paclitaxel) trial by Micheal Werk at Charite, Universitätsmedizin Berlin, enrolled 87 patients from 2004 to 2006 with stenosis or occlusion of SFA or popliteal artery [21]. They were randomized to receive either the standard balloon angioplasty or the propriety Paccocath paclitaxel balloon [17]. At 6 months follow up those treated with DEB showed lower restenosis of 19 percent compared to the control group with 47 percent $(p=0.035)$ [19]. The trial had an 18 and 24 month follow up period.

Both Thunder and FemPac trials were initiated at almost the same time at different hospitals. and demonstrated that short term exposure to paclitaxel reduces restenosis. These trials were limited in design with small sample size, heterogeneous population sample, and short-term endpoints.

The DEBELLUM (Drug-Eluting Balloon Evaluation for Lower Limb Multilevel Treatment) study enrolled 50 patients collectively presenting with 122 lesions, either femoropopliteal (75.4 percent) or below the knee (24.6 percent), randomized to receive either DEB or conventional angioplasty balloon therapy. At six months, endpoint TLR in DEB group was 6.1 percent compared to 23.6 percent for control group. This trial was conducted from 2010 to 2011 by Fabrizio Fanelli, University of Rome, Italy. Binary restenosis was 9.1 percent in DEB group versus 28.9 percent in the control group [22].

The Advance 18 PTX (paclitaxel) trial compared Advance 18 PTX paclitaxel balloon by Cook Medical (Bloomington, IN) to the uncoated Advance 18LP balloon catheter. The trial was to initially enroll 100 patients but then increased the number by 50 patients to improve the statistical power of the study [23]. It is not approved for use in the US.

The INPACT-DEEP trial by Medtronic Endovascular studied IN.PACT Amphirion paclitaxel coated balloons with standard PTA balloons. The study was started in 2009 and aimed to enrolled 358 patients with CLI in Europe [23]. In November 2013 Medtronic, Inc. (Minneapolis, MN) stopped production of its IN. PACT Amphirion in USA and had a recall when 12 months follow up showed no difference between IN.PACT Amphirion and conventional angioplasty balloon [25]. There was also an increased rate of amputation in the patients who had received DEB treatment (8.8 percent) than the ones who had angioplasty (3.6 percent) with $p=0.08$ [26].

Medtronic, Inc. has various types of DCB under research in its IN.PACT clinical programs, including IN.PACT Pacific ${ }^{\mathrm{TM}}$ (PACIFIER study), IN.PACT Falcon ${ }^{\mathrm{TM}}$ (BELLO study for coronary artery disease) and IN.PACT Admiral ${ }^{\mathrm{TM}}$ (SFA study). These clinical programs include 24 studies across 80 countries with almost 4,000 patients at 200 sites [27].

In 2012 the international IN.PACT Global SFA was initiated, testing Medtronic's IN.PACT Admiral ${ }^{\mathrm{TM}}$ drug eluting balloon in 1,500 patients with femoropopliteal lesions Now in the US IN.PACT Admiral ${ }^{\mathrm{TM}}$ is an investigational medical device under an IDE (investigational device exemption) category by the FDA. IN.PACT Admiral ${ }^{\mathrm{TM}}$ has a proprietary coating of paclitaxel with urea called FreePac ${ }^{\mathrm{TM}}[28]$. 
The IN.PACT SFA Admiral ${ }^{\mathrm{TM}}$ trial has two parts, a European arm IN.PACT SFA I enrolling 150 patients in Europe at 17 sites while a US arm IN.PACT SFA II enrolling 181 patients at 40 US sites [28].

The PACIFIER (Paclitaxel-coated Balloons in Femoral Indication to Defeat Restenosis) study results were presented in the 2012 EuroPCR congress. The study used Medtronic's IN.PACT Pacific ${ }^{\mathrm{TM}}$ drug eluting balloon versus conventional non-coated balloons with an enrollment of 91 patients from three hospitals in Germany [37-27]. At 12 months the result showed that the target lesion revascularization (TLR) for IN.PACT Pacific ${ }^{\mathrm{TM}}$ was 7.1 percent versus 34.9 percent for the control $(p=0.003)[29]$.

The DEBATE SFA study (Drug Eluting Balloon in peripheral intervention) evaluated $\mathrm{DEB}$ angioplasty followed by nitinol stent placement versus non-drug coated PTA followed by nitinol stent placement. The study enrolled 104 patients with 110 femoropopliteal lesions. Fifty one (51) patients got conventional angioplasty with nitinol stent placement, while 53 patients ( 55 lesions) got the IN.PACT Admiral $^{\mathrm{TM}}$ (Medtronic Invatec) DCB with nitinol stent. It was conducted from 2009 to 2011 in Italy by Leonardo Bolognese, MD at Ospedale S Donato with Francesco Liistro, San Donato Hospital, Italy as the principal investigator [30]. Binary restenosis (reduction in vessel diameter stenosis of 50 percent or more) at 12 months follow up was 17 percent in the IN.PACT Admiral ${ }^{\mathrm{TM}}$ receiving group and 43 percent in the conventional treatment group $(p=0.001)$. TLR was 16 percent in the IN.PACT Admiral ${ }^{\mathrm{TM}}$ group and 33 percent in the conventional treatment group ( $p=0.07$ ) [31]. The study was presented in October 2012 at the 24th annual Transcatheter Cardiovascular Therapeutics (TCT) scientific symposium, sponsored by the Cardiovascular Research Foundation (CRF). The paclitaxel eluting balloon IN.PACT Admiral ${ }^{\mathrm{TM}}$ by Medtronic Invatec was used for this study.

The Lutonix LEVANT I (Paclitaxel-Coated Balloon for the Prevention of Femoropopliteal Restenosis) study using Moxy DCB by Lutonix, Inc. (Maple Grove, MN) enrolled 101 patients in Belgium and Germany to test Lutonix paclitaxel drug coated balloons versus conventional balloon angioplasty in from June to December of 2009 [17]. Patency with Lutonix DCB was 71.8 percent while those treated with conventional balloon angioplasty was 48.6 percent [32].

LEVANT 2 trial started in 2011 to 2014 randomized 476 patients using paclitaxel coated Moxy balloon or standard balloon at 54 worldwide sites, with 42 in USA and 12 in Europe. Kenneth Rosenfield, M.D., Massachusetts General Hospital, Harvard University School of Medicine, was the principal investigator for the study sites in the US. LEVANT 2 clinical trials showed a better vessel patency of 73.5 percent with Lutonix than with conventional PTA patency of 56.8 percent $(p$ $=0.001$ ). There was an a sustained improvement in the Rutherford scores and low rate of reintervention for restenosis. The LEVANT 2 along with LEVANT I, LEVANT 2 Continued Access (started in 2012, $\mathrm{N}=657$ ), and LEVANT 2 Safety Registry [33] in summation added up to 1000 patients and was the basis of submitting Lutonix DCB for approval by the FDA [34]. FDA recently approved Lutonix DCB for use in the US.

The DANCE (dexamethasone infusion to the adventitia to enhance clinical efficacy after femoropopliteal revascularization) study under supervision of Christopher D Owens, M.D., University of California, San Francisco, is investigating the new balloon angioplasty procedure using the Bullfrog drug-delivery catheter by Mercator MedSystems, US, to infuse the anti-inflammatory drug, dexamethasone, by a microneedle into the adventitia of the vessel. The drug is diffused through the vessel from the outside towards the inside, creating a drug eluting vessel reservoir. Enrollment started in February of 2011. By September 2012 twenty patients had been enrolled and results were presented at the MEET (Multidisciplinary European Endovascular Therapy) Congress in Rome, Italy, in June 2013. Results showed improvement in the ABI's on discharge, and at 6- and 12-month follow-up. There was an improvement on the Rutherford scores and six-month patency was comparable to DEB for longer lesions [19].

\section{Recently Presented Breakthrough Trials on Drug Eluting Balloons:}

In 2014 quite, a few DEB related study results and trials were presented at various medical conferences. Some of these are highlighted below.

\section{Viva 14 conference}

IN.PACT SFA II principal investigators are John Laird, M.,at the University of California Davis and Peter Schneider MD, Kaiser Foundation Hospital in Honolulu, Hawaii. The study showed higher primary patency $(89.8 \%$ vs $66.8 \% ; p<0.001)$ and lower Target Lesion Revascularization (TLR) rate $(2.4 \%$ vs $20.6 \% ; p<0.001)$ at 12 months for drug-coated balloon (DCB) versus PTA for femoropopliteal lesions. Diabetic patients in the trial were studied as a subgroup analysis. In the diabetic group 12-month analysis gave a higher primary patency (82.7\% vs $62.3 \% ; p=0.0015)$ and lower TLR ( $3.7 \%$ vs $23.1 \% ; p<0.001)$ for the DCB versus PTA treated diabetic group [35].

The DEFINITIVE AR (Atherectomy Followed by a Drug Coated Balloon to Treat Peripheral Arterial Disease) was designed to compare the benefits of plaque removal via atherectomy followed by DEB or DAART (directional atherectomy and anti-restenosis therapy) with drug coated balloons versus only Drug Coated Balloon (DCB) to treat complex PAD. Thomas Zeller of the Universitaets-Herzzentrum, Bad Krozingen, Germany presented the 12-month results at the Vascular Interventional Advances (VIVA) 2014 conference in Las Vegas. The study enrolled 121 patients from 2011 to May 2014. This trial compared Covidien's TurboHawk ${ }^{\text {twx }}$ or SilverHawk plaque excision systems followed by the Medrad Bayer Healthcare 's Cotavance ${ }^{\mathrm{m} x}$ drug-eluting balloon catheter having Paccocath technology versus the Cotavance balloon catheter alone [36]. This study utilized 10 sites in Europe. The patency rates for the long lesions of $10 \mathrm{~cm}$ or more for the DAART group was 96.8 percent at 12 months, while it was 85.9 percent for the DCB group. For severely calcified lesions, the 12-month patency rate was 70.4 percent in the DAART group and 62.5 percent for the DCB group. Thus, DAART was better than DCB in long and calcified complex lesions [37]. Patients will be followed up for a total of 24 months. This is a pilot study to be followed by larger trials to confirm the promising results of the DAART treatment strategy. Cotavance ${ }^{\mathrm{ma}}$ paclitaxel drug-eluting balloon catheter having Paccocath ${ }^{\text {Tw }}$ technology is approved for use in Europe. Cotavance ${ }^{\mathrm{Tw}}$ production was suspended in US in 2012 due to regulatory requirements by the FDA, citing problems with drug adhesion to the balloon.

A study on lithotripsy technology to disrupt calcification in the SFA and popliteal artery, DISRUPT PAD, was also presented on the second day of the VIVA 14 conference by Marianne Brodmann, M.D., from the Medical University of Graz, Austria [38]. This trial used Lithoplasty balloon by Shockwave Medical in 35 patients with calcified stenosis. Device success was at 87 percent with residual stenosis of only 23 percent. Follow up was targeted at 30 days and 6 months. 30-day patency was 100 percent. Unlike other devices that target superficial 
calcification, Lithotripsy may prove to have an effect on deep calcium deposition in vessel wall as well [39].

\section{Charing Cross Symposium}

Medtronic presented one-year results of the IN.PACT SFA study at the Charing Cross Symposium held in London in April 2014. The IN.PACT Admiral ${ }^{\mathrm{TM}}$ DCB showed a vessel patency rate of 82.2 percent, while for plain angioplasty without IN.PACT Admiral was 52.45 percent $(p<0.001)$. The freedom from target lesion revascularization (TLR) was 97.6 percent with IN.PACT Admiral ${ }^{\mathrm{TM}}$ and 79.4 percent with conventional angioplasty [40]. In US the IN.PACT Admiral ${ }^{\mathrm{TM}}$ $\mathrm{DEB}$ is allowed for investigational use by the FDA.

\section{EuroPCR}

Covidien, a healthcare products company headquartered in Ireland, initiated the ILLUMENATE trials to test the Stellarex drug coated balloons. Henrik Schröder, MD, at the Vascular Center-Jewish Hospital, Berlin, Germany, conducted the ILLUMENATE FIH trial sponsored by Covidien, a healthcare products company. In the May 2014 EuroPCR Scientific Congress (the annual congress of the European Association of Percutaneous Cardiovascular Interventions, EAPCI, which is a registered branch of the European Society of cardiology) held in in Paris, results of the ILLUMENATE First In Human (FIH) trial using paclitaxel eluting Stellarex drug coated balloon (Stellarex DCB) were presented. The balloon used the EnduraCoat technology designed to prevent drug loss during transit and for efficient drug supply to the lesion site. This trial enrolled 50 patients with a total of 58 lesions in the SFA and / or popliteal artery. The study showed an 82.3 percent patency at 24 months follow up and freedom from target lesion revascularization rate of 87.9 percent [41].

The ILLUMENATE Pivotal trial is being conducted in 35 centers in the USA and has a goal to enroll 360 patients, conducted by Prakash Krishnan, M.D., at Mount Sinai Medical Center in New York, and Sean Lyden, MD, at the Cleveland Clinic Lerner College of Medicine in Cleveland, Ohio.

The ILLUMENATE PK pharmacokinetics trial by Andrew Holden, M.D., at the at The Auckland City Hospital, New Zealand, started enrollments in 2013, with a goal to enroll 25 patients.

The European ILLUMENATE EU trial by Henrik Schroeder, MD, at The Jewish Hospital in Berlin, Germany, is set to enroll upto 360 patients at 30 European centers.

The ILLUMENATE Global trial aims to enroll 500 patients from 65 centers worldwide [42].

\section{FDA approval for Lutonix Dcb}

In October 2014 the FDA (U.S. Food and Drug Administration) approved Lutonix 035 drug coated balloon (Lutonix DCB) by Lutonix, Inc. of New Hope, Minnesota (which was acquired by C. R. Bard Inc. in 2011), as the first DEB angioplasty catheter to be used in the US for femoropopliteal PAD disease. It has been in use in Europe since 2012. The obstructed vessel is first mechanically dilated with a noncoated balloon followed by paclitaxel coated Lutonix balloon catheter to dispense the drug [32]. It is used to treat the superficial femoral or popliteal artery a stenotic or restenotic lesion of upto $150 \mathrm{~mm}$ with the vessel having a $4-6 \mathrm{~mm}$ diameter [43]. FDA has instructed on conducting further two follow up studies, one to monitor the safety and effectiveness of Lutonix in 657 patients post PTA procedure, and one targeted specifically at female patients to observe any differences in this population group [44].

Medtronic has submitted its data to the FDA of its IN.PACT Admiral $^{\mathrm{TM}}$ drug coated balloon for approval by June 2015 [45].

A list of DEB with their FDA approval status is given in table 1 [46].

\section{Future of DEB}

The field of endovascular treatments using percutaneous methods for peripheral vascular disease especially in the lower limbs has come a long way, widely replacing open surgery, and will continue to grow and expand. Current research and data in this area is still lagging behind compared to that for coronary interventions. About 50 million people in the US and Europe are suffering from PAD [27]. Improvement in long-term efficacy, safety, and patency is continuing with new innovational technologies in balloon angioplasty technologies, particularly drug eluting balloon angioplasty. For now, paclitaxel is the only drug being used in DEB, but some trials are looking at other drugs like dexamethasone as well. Different doses, excipients and release kinetics for paclitaxel are also being tested. Though DEB alone is showing promising results, studies comparing Drug Eluting Balloons (DEB) to Drug Eluting Stents (DES) have mixed results. DEB is also shown to be more safe and effective in femoropopliteal disease than uncoated balloon angioplasty. Calcified and bulky lesions may still require stenting and atherectomy but the use of DEB with stenting and DEB following atherectomy needs to be further evaluated. Improved designs need to be examined to treat longer SFA lesions and for belowthe-knee lesions.

DEB's generally have a higher price tag than non-coated standard balloons. However, many companies are investing in DEB's growing market which will eventually lead to lower sale prices. According to iData Research Inc. the global market for DEB is predicted to by a Compound Annual Growth Rate (CAGR) of 25 percent [47]. Global

Table 1. DEB devices and FDA approval status (Source: Wild et al. BMC Cardiovascular Disorders 2014;14:154)

\begin{tabular}{|c|c|c|c|}
\hline Intervention & Product / Manufacturer & Level of Evidence & Level of FDA Approval \\
\hline $\begin{array}{l}\text { Percutaneous transluminal angioplasty } \\
\text { (PTA) of periphery arteries with drug-eluting } \\
\text { balloon (DEB) }\end{array}$ & $\begin{array}{l}\text { In.Pact }^{\mathrm{TM}} \text { Amphirion + Admiral /Medtronic } \\
\text { Lutonix DCB }^{\mathrm{TM}} / \text { Bard-Lutonix } \\
\text { Cotavance }^{\mathrm{TM}} / \text { Bayer Schering } \\
\text { Advance } 18 \mathrm{PTX}^{\circledR} / \text { Cook Medical } \\
\text { LEGflow }^{\mathrm{TM}} / \text { Cardionovum } \\
\text { ELUTAX SV }^{\mathrm{TM}} / \text { Aachen Resonance } \\
\text { Freeway }^{\mathrm{TM}} / \text { Eurocor }^{\mathrm{T}}\end{array}$ & $\begin{array}{l}\text { 2013: } 4 \text { RCTs, } 50-102 \text { pts }\left(2 \times \text { In.Pact }^{\mathrm{TM}}\right. \\
\text { DEBELLUM, PACIFIER, } 2 \times \text { Cotovance }^{\mathrm{TM}} \\
\text { THUNDER, FemPac) }+2 \text { cohort studies } \\
\text { (registries: In.Pact }{ }^{\mathrm{TM}} \text { Admiral, In.Pact }{ }^{\mathrm{TM}} \\
\text { Amphirion) }\end{array}$ & $\begin{array}{l}\text { FDA } 2014 \text { Approved: } \text { Lutonix DCB }^{\circledR} \\
\text { PMA based on LEVANT } 2 \text { RCT, } 476 \text { pts }+ \\
\text { LEVANT } 2 \text { registry, } 657 \text { pts. } \\
\text { IDE Status: In.Pact }{ }^{\mathrm{TM}} \text { Admiral based on SFA I } \\
\text { and SFA II RCT, } 331 \text { pts } \\
\text { No IDE Status: Cotavance } \\
\text { suspended), Advance } 18 \text { PTX (only EU), }^{\mathrm{TM}} \text { (IDE } \\
\begin{array}{l}\text { LEGflow } \\
\text { (only EU) }\end{array}\end{array}$ \\
\hline
\end{tabular}


Data forecasts the US to have the largest share in the ever-expanding DEB market among 10 countries covered by a report, with the US market amounting to almost 26 percent by 2019 [48]. The global market growth may, however, be affected by lack of sufficient clinical data and reimbursement issues in countries like India, France and Brazil. Once the cost of drug-coated balloons is reduced, the procedure can be cost effective and the long-term health benefits of DEB can be experienced by patients. This growing market needs to be met with reliable medical evidence of the safety and credibility of these DEB's. Patients' safely and health need to be of foremost importance with strict regulations and reporting protocols. Comparing DEB to other treatments for CLI is needed to provide comparative data on longterm outcomes. Interventional cardiologists, radiologists, researchers, government regulatory bodies, and the healthcare industry need to be vigilant in collecting information on long-term outcomes to support decision making and pave way for improved DEB device technologies.

\section{References}

1. 'IN.PACT Admiral' Drug-Coated Balloon From Medtronic Outperforms Standard Angioplasty In Landmark Study. Medtronic Newsroom, News and Information. April 5 2014. Available at: http://newsroom.medtronic.com/phoenix.zhtml?c=251324\&p=irolnewsArticle \&ID=1916027

2. Acute limb ischemia. Wikipedia, the free encyclopedia. 2006. Available at: http:// en.wikipedia.org/wiki/Acute_limb_ischaemia

3. Peripheral Arterial Disease (PAD) Fact Sheet. Centers for Disease Prevention and Control. 2011. Available at: http://www.cdc.gov/dhdsp/data_statistics/fact_sheets/ fs pad.htm Accessed: December 6, 2014.

4. Norgren L, Hiatt WR, Dormandy JA, Nehler MR, Harris K A, et al. (2007) Inter-society consensus for the management of peripheral arterial disease (TASC II). J Vasc Surg 33: S1-S75. [Crossref]

5. John W. Hallett. Peripheral Arterial Disease. The Merck Manual Professional Edition. 2011. Available at: http://www.merckmanuals.com/professional/cardiovascular disorders/peripheral_arterial_disorders/peripheral_arterial_disease.

6. White CJ, Gray WA (2007) Endovascular therapies for peripheral arterial disease an evidence-based review. Circulation 116: 2203-2215. [Crossref]

7. Ouriel K (2001) Peripheral arterial disease. Lancet 358: 1257-1264. [Crossref]

8. Paul Harasim. Laser eliminates dangerous plaque caused by peripheral artery disease. Las Vegas Review-Journal. June 1, 2014.

9. Peripheral artery disease. Vascular and Interventional radiology. 2013. Available at: http://virchicago.com/peripheral-artery-disease/

10. Muller DK. Peripheral vascular stent insertion. Medscape. Available at: http:// emedicine.medscape.com/article/1839716-overview

11. Fogarty TJ, White RA. Peripheral endovascular interventions. Springer. June 25, 2010

12. Angioplasty. Wikipedia, the free encyclopaedia. 2006. Available at: http://en.wikipedia. org/wiki/Angioplasty\#cite_note-11

13. History of Angioplasty Timeline. Angioplasty.org. 2005. Available at: http://www.ptca. org/nv/timeline.

14. Drug-eluting stent. Wikipedia, the free encyclopaedia. 2006. Available at: http:// en.wikipedia.org/wiki/Drug-eluting_stent

15. Dake MD, Ansel GM, Jaff MR, Ohki T, Saxon RR, et al. (2016) Durable clinical effectiveness with paclitaxel-eluting stents in the femoropopliteal artery: 5-year results of the Zilver PTX randomized trial. Circulation 133:1472-1483. [Crossref]

16. Waksman R, Pakala R (2009) Drug-Eluting Balloon the Comeback Kid? Circ Cardiovasc Interv 2: 352-358 [Crossref]

17. Scheller B, Cremers B, Schmitmeier S, Schnorr B, Clever Y (2010) Drug-coated balloons-History and peripheral vascular opportunities. ICR 5: 70-73.

18. European Approval Granted for Cotavance Drug-Eluting Balloon. Diagnostic and Interventional Cardiology. May 18, 2011. Available at: http://www.dicardiology.com/ article/european-approval-granted-cotavance-drug-eluting-balloon .

19. Pastromas G, Katsanos K, Krokidis M, Karnabatidis D, Spiliopoulos S (2014) Emerging stent and balloon technologies in the femoropopliteal arteries. Scientific World Journal 2014: 695402. [Crossref]
20. Chan YC, Cheng SW (2011) Drug-eluting stents and balloons in peripheral arterial disease: evidence so far. Int J Clin Pract 65: 664-668. [Crossref]

21. Werk M, Langner S, Reinkensmeier B, Boettcher HF, Tepe G et al. (2008) Inhibition of restenosis in femoropopliteal arteries paclitaxel-coated versus uncoated balloon femoral paclitaxel randomized pilot trial. Circulation 118: 1358-1365. [Crossref]

22. Six-month results from DEBELLUM trial of drug-eluting treatment for periphera arterial disease published. Interventional News. October 16, 2012. Available at: http:/ www.cxvascular.com/in-latest-news/interventional-news---latest-news/six-month-resultsfrom-debellum-trial-of-drug-eluting-treatment-for-peripheral-arterial-disease-published

23. Drug-Eluting Balloons in the SFA. Endovascular Today. March 2010. Available at: http://evtoday.com/2010/03/drug-eluting-balloons-in-the-sfa

24. Zeller T, Baumgartner I, Scheinert D, Brodmann M, Bosiers M, et al. (2014) Drugeluting balloon versus standard balloon angioplasty for infrapopliteal arterial revascularization in critical limb ischemia: 12-month results from the IN.PACT DEEP randomized trial. J Am Coll Cardiol 64: 1568-1576. [Crossref]

25. Medtronic Recalls In.Pact Amphirion DEB for Below-the-Knee. Endovascular Today December 4, 2013. Available at: http://evtoday.com/2013/12/04/medtronic-recallsinpact-amphirion-deb-for-btk-disease-based-on-trial-results

26. IN.PACT DEEP: DEB noninferior to PTA but may increase amputation rates Healio. Cardiology todays intervention. October 10, 2014. Available at: https:/ www.healio.com/cardiology/intervention/news/online/\%7B0798f941-7cf4-429dbfbd-80e464307b79\%7D/inpact-deep-deb-noninferior-to-pta-but-may-increaseamputation-rates

27. 'IN.PACT Admiral' Drug-Coated Balloon From Medtronic Outperforms Standard Angioplasty In Landmark Study. Medtronic. News and Information. April 5, 2014 Available at: http://newsroom.medtronic.com/phoenix.zhtml?c=251324\&p=irolnewsArticle \&ID=1916027

28. Medtronic Drug-Eluting Balloon Study Completes Enrollment: IN.PACT SFA II CathLab Digest. February 2013;21(2). Available at: http://www.cathlabdigest.com/articles/ Medtronic-Drug-Eluting-Balloon-Study-Completes-Enrollment-INPACT-SFA-II

29. Medtronic IN.PACT Drug-Eluting Balloon Studies Show Significant Benefit of Novel Medical Device in Treating Narrowed Arteries. Medtronic. News and Information. may 16, 2012. Available at: http://investorrelations.medtronic.com/phoenix $\mathrm{zhtml}$ ? $=251324 \& \mathrm{p}=$ irol-newsArticle $\&$ ID $=1769483$

30. Drug Eluting Balloon in peripherAl inTErvention SFA (DEBATE SFA). ClinicalTrials gov. 2012. Available at: http://clinicaltrials.gov/ct2/show/NCT01556542

31. Study Finds Widening Leg Arteries with DEBs Prior to Stenting Reduces Recurrences of Blockages. Diagnostic and Interventional Cardiology. October 23, 2012. Available at: http://www.dicardiology.com/article/study-finds-widening-leg-arteries-debs-priorstenting-reduces-recurrences-blockages

32. FDA approves first drug-coated angioplasty balloon catheter to treat vascular disease. FDA News and Events. October 10, 2014. Available at: http://www.fda.gov/ NewsEvents/Newsroom/PressAnnouncements/ucm418455.htm

33. Why Lutonix ${ }^{\circledR}$ 035. Bard Peripheral Vascular. US vascular products. Available at http://173.165.132.149/bardpv/_vascular/whyLutonix.php

34. Bard Submits Final PMA Module to the FDA for the Lutonix Drug-Coated Balloon Bard News Release. November 25, 2013. Available at: http://investorrelations.crbard. com/phoenix.zhtml?c=91501\&p=irol-newsArticle \&ID=1879892

35. Late-breaking Clinical Trial Results Announced At VIVA 14. gnomes national news service. November 4, 2014. Available at: http://news.gnom.es/pr/late-breaking-clinicaltrial-results-announced-at-viva-14

36. Atherectomy Followed by a Drug Coated Balloon to Treat Peripheral Arterial Disease (DEFINITIVE AR). ClinicalTrials.gov. 2011. Available at: http://clinicaltrials.gov/ct2/ show/NCT01366482

37. Covidien Announces 12-Month DEFINITIVE AR Results at VIVA 14. Covidien News Release. November 4, 2014. Available at: http://www.covidien.com/news/phoenix. zhtml?c=216712\&p=irol-newsArticle\&ID $=1985578$

38. Shockwave Medical's Lithoplasty Balloon Catheters Evaluated in DISRUPT PAD Endovascular Today. November 5, 2014. Available at: http://evtoday.com/2014/11/06/ shockwave-medicals-lithoplasty-balloon-cathethers-evaluated-in-disrupt-pad

39. Second Day of Late-Breaking Clinical Trial Results at VIVA 14. PR Newswire. November 5, 2014. Available at: http://www.prnewswire.com/news-releases/secondday-of-late-breaking-clinical-trial-results-at-viva-14-281701651.html

40. LEVANT 2 one-year results presented at FDA panel meeting. VascularNews. June 13 2014. Available at: http://www.cxvascular.com/vn-latest-news/vascular-news---latestnews/levant-2-one-year-results-presented-at-fda-panel-meeting 
41. Covidien Releases Two-Year Study Results Demonstrating Sustained Effectiveness of Drug-Coated Angioplasty Balloon Technology. Marketwatch. May 22, 2014. Available at: http://www.marketwatch.com/story/covidien-releases-two-year-studyresults-demonstrating-sustained-effectiveness-of-drug-coated-angioplasty-balloontechnology-2014-05-22

42. Covidien Initiates ILLUMENATE Trials for the Stellarex. Endovascular Today. July 15, 2013. Available at: http://evtoday.com/2013/06/covidien-initiates-illumenate-trialsfor-the-stellarex-peripheral-drug-coated-balloon

43. Tracy Walker. FDA approves first drug-coated balloon catheter. Modern Medicine Network. Formulary Journal. October 10, 2014. Available at: http://formularyjournal modernmedicine.com/formulary-journal/content/tags/angioplasty/fda-approves-firstdrug-coated-balloon-catheter?

44. First drug-eluting balloon approved in USA. VascularNews. October 10, 2014. Available at: http://www.cxvascular.com/vn-latest-news/vascular-news---latest-news/ first-drug-eluting-balloon-approved-in-usa
45. Stacy Lawrence. Medtronic readies for 2015 drug-eluting balloon FDA approval Fierce Medical Devices. June 11. 2014. Available at: http://www.fiercemedicaldevices. com/story/medtronic-readies-2015-drug-eluting-balloon-fda-approval/2014-06-11

46. Wild C, Erdös J, Zechmeister I (2014) Contrasting clinical evidence for market authorisation of cardio-vascular devices in Europe and USA: a systematic analysis of 10 devices based on Austrian pre-reimbursement assessments. BMC Cardiovascular Disorders 14: 154

47. Kamran Zamanian. Evaluating the Global Markets for Drug-Coated Balloons, Transcatheter Heart Valves. MED Device Online. April 30, 2014. Available at: http:/ www.meddeviceonline.com/doc/evaluating-the-global-markets-for-drug-coatedballoons-transcatheter-heart-valves-0001

48. Drug-eluting balloon revenue to more than double by 2019. Cardiovascular News. October 31, 2013. Available at: http://www.cxvascular.com/cn-latest-news/ cardiovascular-news---latest-news/drug-eluting-balloon-revenue-to-more-thandouble-by-2019

Copyright: (C2018 Khan UJM. This is an open-access article distributed under the terms of the Creative Commons Attribution License, which permits unrestricted use, distribution, and reproduction in any medium, provided the original author and source are credited. 